\title{
Phase II study of cetuximab in combination with cisplatin and docetaxel in patients with untreated advanced gastric or gastro-oesophageal junction adenocarcinoma (DOCETUX study)
}

\author{
C Pinto*, , F Di Fabio', C Barone ${ }^{2}$, S Siena ${ }^{3}$, A Falcone ${ }^{4}$, S Cascinu ${ }^{5}$, FL Rojas Llimpe', G Stella ${ }^{6}$, G Schinzari ${ }^{2}$, \\ S Artale ${ }^{3}$, V Mutri', S Giaquinta', L Giannetta ${ }^{3}$, A Bardelli' $^{6}$ and AA Martoni' \\ 'Department of Medical Oncology, S. Orsola-Malpighi Hospital, Bologna, Italy; ${ }^{2}$ Department of Medical Oncology, Gemelli Hospital, Rome, Italy; \\ ${ }^{3}$ Department of Medical Oncology, Falck Division, Niguarda Cà Granda Hospital, Milan, Italy; ${ }^{4}$ Department of Medical Oncology, University of Pisa, \\ Pisa, Italy; ${ }^{5}$ Department of Medical Oncology, University of Marche, Ancona, Italy; ${ }^{6}$ Laboratory of Molecular Genetics, Institute for Cancer Research \\ and Treatment, University of Turin, Candiolo, Italy
}

BACKGROUND: The conventional treatment options for advanced gastric patients remain unsatisfactory in terms of response rate, response duration, toxicity, and overall survival benefit. The purpose of this phase II study was to evaluate the activity and safety of cetuximab combined with cisplatin and docetaxel as a first-line treatment for advanced gastric or gastro-oesophageal junction adenocarcinoma.

METHODS: Untreated patients with histologically confirmed advanced gastric or gastro-oesophageal adenocarcinoma received cetuximab at an initial dose of $400 \mathrm{mg} \mathrm{m}^{-2}$ i.v. followed by weekly doses of $250 \mathrm{mg} \mathrm{m}^{-2}$, cisplatin $75 \mathrm{mg} \mathrm{m}^{-2}$ i.v. on day I, docetaxel $75 \mathrm{mg} \mathrm{m}^{-2}$ i.v. on day I, every 3 weeks, for a maximum of 6 cycles, and then cetuximab maintenance treatment was allowed in patients with a complete response, partial response, or stable disease.

RESULTS: Seventy-two patients (stomach $81.9 \%$ and gastro-oesophageal junction 18.1\%; locally advanced disease 4.2\%; and metastatic disease 95.8\%) were enrolled. The ORR was 4I.2\% (95\% Cl, 29.5-52.9). Median time to progression was 5 months (95\% Cl, 3.7-5.4). Median survival time was 9 months $(95 \% \mathrm{Cl}, 7-\mathrm{II})$. The most frequent grades $3-4$ toxicity was neutropenia (44.4\%). No toxic death was observed.

CONCLUSIONS: The addition of cetuximab to the cisplatin/docetaxel regimen improved the ORR of the cisplatin/docetaxel doublet in the first-line treatment of advanced gastric and gastro-oesophageal junction adenocarcinoma, but this combination did not improve the TTP and OS. The toxicity of cisplatin/docetaxel chemotherapy was not affected by the addition of cetuximab.

British Journal of Cancer (2009) I 01, I26 I-1268. doi:10.1038/sj.bjc.6605319 www.bjcancer.com

Published online 22 September 2009

(c) 2009 Cancer Research UK

Keywords: advanced gastric cancer; cetuximab; cisplatin/docetaxel

Gastric cancer is a considerable health problem worldwide and as such remains a major challenge for the whole oncology community. For the year 2007, gastric cancer was estimated to be the second leading cause of cancer death among men and the fourth among women, with an expectancy of 800000 cancer-related deaths overall (Parkin et al, 2005). There is remarkable geographic variation, with $60 \%$ of cases arising in Eastern Asia (Kelley and Duggan, 2003; Parkin et al, 2005; Garcia et al, 2007). In the European Union, for the year 2002, the number of deaths from gastric cancer was 40759 among men and 27980 among women (Bosetti et al, 2008). In the same year, in Italy, stomach cancers accounted for $6.7 \%$ of cancer deaths in both sexes with 6266 deaths in men and 4686 in women (Malvezzi et al, 2008). Although the

*Correspondence: C Pinto, Medical Oncology Unit, S. Orsola-Malpighi Hospital, Via Albertoni I5, Bologna 40I38, Italy;

E-mail: carmine.pinto@aosp.bo.it

Received I5 April 2009; revised 4 August 2009; accepted 20 August 2009; published online 22 September 2009 incidence of gastric cancer is declining in the Western world, adenocarcinomas of the gastro-oesophageal junction (GEJ) are increasing in number (Kelley and Duggan, 2003; Parkin et al, 2005; Garcia et al, 2007; Bosetti et al, 2008; Malvezzi et al, 2008).

In patients with resectable cancer, surgery and perioperative therapy are potentially curative treatments. However, the majority of patients with gastric cancer had stage III or IV disease at presentation and thus are candidates for palliative chemotherapy. In advanced disease, the median survival in patients not receiving chemotherapy is 3-4 months. A systematic meta-analysis of randomised studies found a statistically significant advantage of chemotherapy compared with the best supportive care and combination of three-drug regimens containing 5-fluorouracil, anthracyclines, and cisplatin (Wagner et al, 2006). New triplet and doublet combinations incorporating docetaxel, oxaliplatin, irinotecan, capecitabine, and S-1 have been evaluated in randomised trials. Although little progress has been made in these trials towards improving the median overall survival time beyond 9 months, the outcome of advanced disease is still disappointing 
(Van Cutsem et al, 2006; Cunningham et al, 2008; Dank et al, 2008; Koizumi et al, 2008; Ajani et al, 2009; Kang et al, 2009).

The conventional treatment options for advanced gastric patients remain unsatisfactory in terms of response rate, response duration, toxicity, and overall survival benefit. Targeted agents are therefore being investigated in an effort to improve the clinical outcome of gastric cancer patients.

The epidermal growth factor receptor (EGFR) is a transmembrane glycoprotein that is a member of the tyrosine kinase growth factor receptor superfamily. The EGFR represents an important therapeutic target in cancer. The EGFR is expressed in many normal human tissues and has been found to be overexpressed in a large variety of tumours (Ciardiello and Tortora, 2001). In gastric cancer, EGFR is overexpressed in $18-91 \%$ of primary tumours and/or metastasis and correlated with a poor prognosis (Tokunaga et al, 1995; Albanell et al, 2001; Mendelsohn, 2002; Takehana et al, 2003; Pinto et al, 2007). Cetuximab (Erbitux, Merck KgaA, Darmstadt, Germany) is a human-murine chimeric monoclonal antibody directed to the EGFR binding site. Cetuximab in metastatic colorectal cancer added to standard chemotherapy produces an improvement in the response rate in randomised studies in both a first-line setting and in patients with refractory disease (Cunningham et al, 2004; Sobrero et al, 2008; Bokemeyer et al, 2009; Van Cutsem et al, 2009). Cetuximab in combination with chemotherapy regimens containing irinotecan (Pinto et al, 2007; Kanzler et al, 2009), oxaliplatin (Lordick et al, 2007; Han et al, 2008, 2009), and cisplatin (Zhang et al, 2008; Yeh et al, 2009) as first-line therapy of advanced gastric or GEJ adenocarcinoma has also shown promising results.

The docetaxel and cisplatin (DC) combination is an active regimen in advanced gastric cancer patients, and it yielded a response rate of $18.5-26 \%$ in two randomised phase II studies (Ajani et al, 2005; Roth et al, 2007). In preclinical studies, cetuximab enhances the activity of cisplatin (Steiner et al, 2007) and docetaxel (Nakata et al, 2004). Given these data, this phase II study was performed to evaluate the efficacy and toxicity of a regimen combining a targeted therapy, cetuximab with cisplatin and docetaxel chemotherapy, for unresectable locally advanced or metastatic gastric and GEJ adenocarcinoma.

\section{PATIENTS AND METHODS}

\section{Study design}

We conducted a multicentre phase II study that was approved by the local ethics committee, registered with the health authorities, and performed according to the guidelines of good clinical practice and the Declaration of Helsinki. The primary end point was objective response (ORR). Secondary end points were toxicity, median survival time (OS), and time to progression (TTP).

\section{Patient and treatment}

Patients with advanced, unresectable, histologically confirmed adenocarcinoma of the stomach or GEJ were assessed for eligibility. The eligibility criteria were: age $\geqslant 18$ years, Karnofsky performance status (KPS) $\geqslant 70$, life expectancy $>3$ months, no earlier treatment with chemotherapy or radiation therapy, neutrophil count $\geqslant 1500$ per $\mu \mathrm{l}$, platelet count $\geqslant 100.000$ per $\mu \mathrm{l}$, haemoglobin $\geqslant 9.0 \mathrm{~g} \mathrm{dl}^{-1}$, serum creatinine $\leqslant 1.5 \times$ upper limit of normal (ULN), ALT and AST $\leqslant 2.5 \times$ ULN $(\leqslant 5 \times$ ULN in the presence of liver metastases), total bilirubin $\leqslant 1.5 \times$ ULN, measurable disease according to the Response Evaluation Criteria in Solid Tumours (RECIST) (Therasse et al, 2000). Prior chemotherapy for advanced cancer was not allowed. Patients who received adjuvant therapy were eligible provided more than 6 months had elapsed between the end of adjuvant therapy and registration for the study.
All the patients provided written informed consent for this study, which was approved by the ethics committee of each participating institution. Patients were considered ineligible for the trial if they satisfied any of the following criteria: previous exposure to antiEGFR, monoclonal antibodies, signal transduction inhibitors, or EGFR targeting therapy; brain metastasis; concurrent malignancy other than non-melanoma skin cancer, or in situ cervix carcinoma (patients with an earlier malignancy but with no evidence of disease for $>5$ years were allowed to enter the trial); clinically relevant coronary artery disease or a history of myocardial infarction within the last 12 months; acute or subacute intestinal occlusion or history of the inflammatory bowel disease; preexisting neuropathy; known grade 3 or 4 allergic reaction to any of the components of the treatment; pregnancy or lactating status; medical or psychological condition which, in the investigator's opinion, would not enable the patient to complete the study or knowingly sign the informed consent.

The baseline evaluation included a history, physical examination (including evaluation of vital signs and performance status), recording of concomitant medication, laboratory tests (haematology and clinical chemistry, CEA, CA19.9, CA 72.4), thorax and abdomen computed tomography or magnetic resonance imaging, and positron emission tomography scan.

In a collateral study, the KRAS and BRAF mutational status was evaluated. Genomic DNA was extracted from paraffin-embedded primary tumour specimens. The mutational status of KRAS (exon 2) and BRAF (exon 15) was ascertained by PCR amplification followed by direct sequencing.

The phase I study was not performed as no significant increase of chemotherapy toxicity was reported in the earlier phase II studies with cetuximab added to the chemotherapy regimens (Lordick et al, 2007; Pinto et al, 2007; Han et al, 2008; Zhang et al, 2008; Han et al, 2009; Yeh et al, 2009; Kanzler et al, 2009).

Patients received cetuximab at an initial dose of $400 \mathrm{mg} \mathrm{m}^{-2}$ i.v. followed by weekly doses of $250 \mathrm{mg} \mathrm{m}^{-2}$, cisplatin $75 \mathrm{mg} \mathrm{m}^{-2}$ i.v. (1-h infusion) plus docetaxel $75 \mathrm{mg} \mathrm{m}^{-2}$ i.v. (1-h infusion) on day 1 every 3 weeks, for a maximum of 6 cycles, and then cetuximab alone was allowed in patients with complete response, partial response, and stable disease (maintenance therapy). Cetuximab premedication comprised antihistamine and corticosteroids i.v. All patients received the following supportive medications: 31 per day hyperhydration; dexamethasone $8 \mathrm{mg}$ (or equivalent drugs) orally administered 12 and $6 \mathrm{~h}$ before docetaxel infusion and $8 \mathrm{mg}$ orally twice daily for 4 days after infusion; 5-hydroxytryptamine3 -inhibitors as emesis prophylaxis. In patients benefiting from combination therapy but developing unacceptable intolerance/ toxicity to cetuximab or cisplatin/docetaxel, cisplatin/docetaxel or cetuximab may be continued as a single treatment and vice-versa. Surgery of locally advanced gastric cancer could be performed during the study at the time of maximum regression under the earlier assessment of the tumour response after at least 12 weeks of treatment (at least 2 cycles of cisplatin/docetaxel plus cetuximab). If a complete resection was achieved, patients would restart the treatment up to a maximum of 6 treatment cycles (adding pre- and post-surgery treatment).

If a patient experiences grade 3 skin toxicity, cetuximab therapy may be deferred for up to two consecutive infusions without changing the dose level. If the toxicity resolves to grade 2 or less by the following treatment period, the treatment may resume. With the second and third occurrences of grade 3 skin toxicity, cetuximab therapy may again be deferred for up to two consecutive weeks with concomitant dose reductions to 200 and $150 \mathrm{mg} \mathrm{m}^{-2}$, respectively. Patients should discontinue cetuximab if more than two consecutive infusions are withheld or a fourth occurrence of grade 3 skin toxicity occurs despite an appropriate dose reduction. Chemotherapy was continued independently of a temporary interruption of cetuximab. Cetuximab was not withheld for cisplatin/docetaxel-related toxicity. Cisplatin/docetaxel dose 
reduction was planned in the event of severe haematological and/ or non-haematological toxicities. Treatment could be delayed for up to 2 weeks to allow toxicities to resolve; delays of $>2$ weeks required treatment withdrawal. A $15 \mathrm{mg} \mathrm{m}^{-2}$ dose reduction of docetaxel or cisplatin was planned for prolonged ( $>7$ days) grade 4 neutropenia, or thrombocytopenia, grade $\geqslant 2$ liver toxicity. For grade 2 neurotoxicity, the DC doses were reduced by $15 \mathrm{mg} \mathrm{m}^{-2}$. Cisplatin was reduced or discontinued if creatinine clearance was $<60$ or $<40 \mathrm{ml} \mathrm{min}^{-1}$. Treatment was discontinued for persistent grade 3 liver toxicity, anaphylaxis, or fluid retention; grade $\geqslant 3$ neuropathy; or a recurrent toxicity despite dose reductions.

\section{Response and toxicity}

Routine evaluation of patients was performed on a weekly basis during therapy. These evaluations included a physical examination, vital signs, KPS, laboratory haematological and serum chemistry, and the recording of adverse events.

The evaluation tumour response to therapy was based on a computed tomography or magnetic resonance scan. Patients were evaluable for response if they had received at least one course of therapy. In addition, those patients who were developing rapid tumour progression, or those who died of progressive disease before the response evaluation, would also be considered evaluable for response. Also, patients who discontinued treatment, or those who died from a treatment-related toxicity before response evaluation, were considered evaluable for response. The tumour was evaluated every 6 weeks during the treatment and at least every 12 weeks during the follow-up. The RECIST criteria were used to assess the type of response (Therasse et al, 2000). Positron emission tomography scan was performed after 3 weeks, before the second cycle of cisplatin/docetaxel chemotherapy. Toxicity was graded according to the National Cancer Institute Common Toxicity Criteria (CTC) Version 3.0 (National Cancer Institute, Common Toxicity Criteria, 2006).

\section{Statistical analysis}

The statistical design was performed according to Simon's twostage design (Simon, 1989). It was expected that the new regimen would have a targeted response rate $\geqslant 40 \%$. The first stage required at least six or more patients out of 20 to have a confirmed partial or complete response assuming $\mathrm{P} 1=0.40, \mathrm{P} 0=0.25$, with $\alpha=0.05$ and $\beta=0.2$ before proceeding to the second stage. In the second stage, 40 assessable patients could be added and if a total of 24 or more patients achieved a confirmed objective response, then the primary end point would have been met. Seventy-two patients were thus needed to take account of possible attrition. TTP and OS were calculated using the Kaplan-Meier method (Kaplan and Meier, 1958). Descriptive statistics were used for safety evaluation.

\section{RESULTS}

\section{Patient population}

From December 2007 to August 2008, 72 patients, in five Italian centres, were enrolled. All 72 patients were evaluated for safety and OS calculations, and 68 were assessable for response. Four patients were not assessable for ORR because one patient with peritoneal carcinomatosis died as a result of bowel occlusion in week 5 of treatment; one died of gastric bleeding in week 1; one died of bowel perforation in week 3; and 1 left the study because of renal toxicity grade 3 after the first chemotherapy cycle.

The patient characteristics are listed in Table 1 . The majority of patients were males $(66.7 \%)$, their median age being 63 years (range, 18-75) and the median KPS 90 (range, 70-100). GEJ was involved in 13 patients $(18.1 \%)$. The histotype was intestinal adenocarcinoma in 41 patients $(56.9 \%)$ and non-intestinal
Table I Patient characteristics

\begin{tabular}{|c|c|c|c|}
\hline \multirow[b]{2}{*}{ Characteristics } & \multicolumn{3}{|c|}{ No. 72} \\
\hline & No. & & $\%$ \\
\hline \multicolumn{4}{|l|}{ Sex } \\
\hline Male & 48 & & 66.7 \\
\hline Female & 24 & & 33.3 \\
\hline \multicolumn{4}{|l|}{ Age, years } \\
\hline Median & & 63 & \\
\hline Range & & $18-75$ & \\
\hline \multicolumn{4}{|l|}{ Karnofsky performance status } \\
\hline 100 & 31 & & 43.1 \\
\hline 90 & 18 & & 25 \\
\hline 80 & 18 & & 25 \\
\hline 70 & 5 & & 6.9 \\
\hline \multicolumn{4}{|l|}{ Primary tumour site } \\
\hline Stomach & 59 & & 81.9 \\
\hline Gastro-oesophageal junction & 13 & & |8.1 \\
\hline \multicolumn{4}{|l|}{ Histotype } \\
\hline Intestinal adenocarcinoma & 41 & & 56.9 \\
\hline Non-intestinal adenocarcinoma ${ }^{a}$ & 31 & & 43.1 \\
\hline \multicolumn{4}{|l|}{ State of disease } \\
\hline Locally advanced & 3 & & 4.2 \\
\hline Metastatic & 69 & & 95.8 \\
\hline \multicolumn{4}{|l|}{ Prior surgery } \\
\hline Total/partial gastrectomy & 25 & & 34.7 \\
\hline Protesis/anastomosis & 7 & & 9.7 \\
\hline Adjuvant chemotherapy & 9 & & 12.5 \\
\hline 5-FU/AF regimens & 5 & & 55.6 \\
\hline 5-FU/CDDP regimens & 2 & & 22.2 \\
\hline 5-FU/CDDP/EPI regimens & 2 & & 22.2 \\
\hline \multicolumn{4}{|l|}{ Site of disease } \\
\hline Primary & 47 & & 65.3 \\
\hline Lymph nodes & 47 & & 65.3 \\
\hline Liver & 35 & & 48.6 \\
\hline Peritoneum/local recurrence & 26 & & 36.1 \\
\hline Other & 14 & & 19.4 \\
\hline \multicolumn{4}{|l|}{ No. of organs involved } \\
\hline । & 17 & & 23.6 \\
\hline 2 & 27 & & 37.5 \\
\hline$>2$ & 28 & & 38.9 \\
\hline
\end{tabular}

24 (77.4\%) with signet ring cells.

adenocarcinoma in $31(43.1 \%)$. At the baseline of the study, three patients $(4.2 \%)$ had non-resectable locally advanced disease and 69 (95.8\%) had metastatic disease. The majority of patients $(76.4 \%)$ had two or more metastases sites. Nine patients $(12.5 \%)$ had received prior adjuvant chemotherapy. Four patients had adjuvant chemotherapy containing cisplatin.

\section{Treatment administration}

Altogether, 1049 weeks of cetuximab were administered, with a median of 13.5 weeks (range, 1-35), and 325 cycles of cisplatin/ docetaxel, with a median of 5 cycles (range, 1-6). The median relative dose intensity was 1.0 for cetuximab (range, $0.1-1.0$ ), 1.0 for cisplatin (range, 0.5-1.0), and 1.0 for docetaxel (range, $0.3-1.0$ ) (Table 2). 
Cetuximab was discontinued in two patients $(2.8 \%)$ for grade 3 infusion-related reaction during the first administration; no cetuximab reduction dose was performed. One patient stopped docetaxel administration for grade 3 hypersensitivity reaction during the first cycle. At least a one-dose reduction of cisplatin was required in 20 patients $(27.8 \%)$ and of docetaxel in 19 patients $(26.4 \%)$. Neutropenia was the most frequent reason for dose reduction or delay.

Maintenance cetuximab therapy (after 6 cycles of cisplatin/ docetaxel plus cetuximab treatment) was performed in $16(51.6 \%)$ out of 31 eligible patients $(31.6 \%)$. The median duration of maintenance treatment was 10 weeks (range, $2-17$ ).

\section{Response}

The data on the treatment response are listed in Table 3. One patient $(1.5 \%)$ achieved a complete response and 27 patients (39.7\%) achieved a partial response; the ORR was $41.2 \%(95 \% \mathrm{CI}$, $29.5-52.9)$. Twenty-four patients $(33.3 \%)$ had stable disease and 16 patients $(23.5 \%)$ had progressive disease. The disease control rate (complete response plus partial response plus stable disease) was $76.5 \%$. The median time to response was 6 weeks (range, 6-19). The median duration of response was 5 months (range, 1-22 months).

Table 2 Delivery of treatment

\begin{tabular}{lccc}
\hline & Cetuximab & Cisplatin & Docetaxel \\
\hline No. of drug administration & 1049 (weeks) & \multicolumn{2}{c}{325 (cycles) } \\
Median of weeks/cycles & 13.5 & \multicolumn{2}{c}{5} \\
Range & $1-35$ & $1-6$ & 1.0 \\
Median relative dose intensity & 1.0 & 1.0 & $0.3-1.0$ \\
Range & $0.1-1.0$ & $0.5-1.0$ & $19(26.4)$ \\
Dose reduction, no. (\%) & $1(1.4)$ & $20(27.8)$ & $6(8.3)$ \\
Drug discontinuation, no. (\%) & $19(26.4)$ & $8(11.1)$ & $1(1.4)$ \\
$\quad$ Temporary & $2(2.7)$ & 0 & \\
$\quad$ Definitive & & &
\end{tabular}

Table 3 Response rate

\begin{tabular}{lcr}
\hline & \multicolumn{2}{c}{ No. 68 } \\
\cline { 2 - 3 } Response & No. & $\%$ \\
\hline Complete response & 1 & 1.5 \\
Partial response & 27 & 39.7 \\
Overall response rate & 21 & 41.2 \\
95\% Cl) & $(29.5-52.9)$ & \\
Stable disease & 24 & 33.3 \\
Progressive disease & 16 & 23.5 \\
Disease control rate & 52 & 76.5 \\
\hline
\end{tabular}

The objective response was similar in both histotypes (45.9\% for intestinal adenocarcinoma and $35.5 \%$ in non-intestinal adenocarcinoma; $P=0.27$ ). The ORR in patients with grade $\geqslant 2$ skin reactions after cetuximab therapy was higher, but not statistically significantly, than the ORR in patients with $<2$ grade $(P=0.05)$ (Table 4).

Two responding patients with non-resectable locally advanced disease were submitted to surgery. One patient achieved a partial response after 4 cycles of cisplatin/docetaxel plus cetuximab therapy and after gastrectomy R0 received the other 2 cycles of combination therapy and 12 weeks of maintenance cetuximab (patient alive and disease-free after 26 months from the start of treatment); and one submitted to gastrectomy R0 after 6 cycles of combination therapy (patient alive and disease-free after 9 months from the start of treatment). Another responder patient with peritoneal metastases who submitted to gastrectomy after 6 therapy cycles has achieved a pathologic complete response (patient alive with disease relapse 16 months after the start of treatment).

Twenty-five $(34.7 \%)$ patients received a second-line treatment: 13 with 5-fluorouracil, folinic acid and irinotecan (FOLFIRI), 5 with etoposide, folinic acid, and 5-fluorouracil (ELF), 3 with capecitabine, 3 with 5-fluorouracil, and 1 with epirubicin and 5-fluorouracil.

\section{Time-to-progression and survival}

The median follow-up time was 19 months (range, 6-26 months). The median TTP was 5 months (95\% CI, 3.7-5.4) (Figure 1). The median OS time was 9 months (95\% CI, 7-11) (Figure 2). In the setting of patients with at least stable disease after 6 cycles of cisplatin/docetaxel plus cetuximab eligible for cetuximab maintenance treatment, patients treated with maintenance cetuximab $($ No. $=16)$ compared with no-maintenance treatment $($ No. $=15)$ showed a trend for longer TTP of 9.2 months (95\% CI, 8.1-10.1)

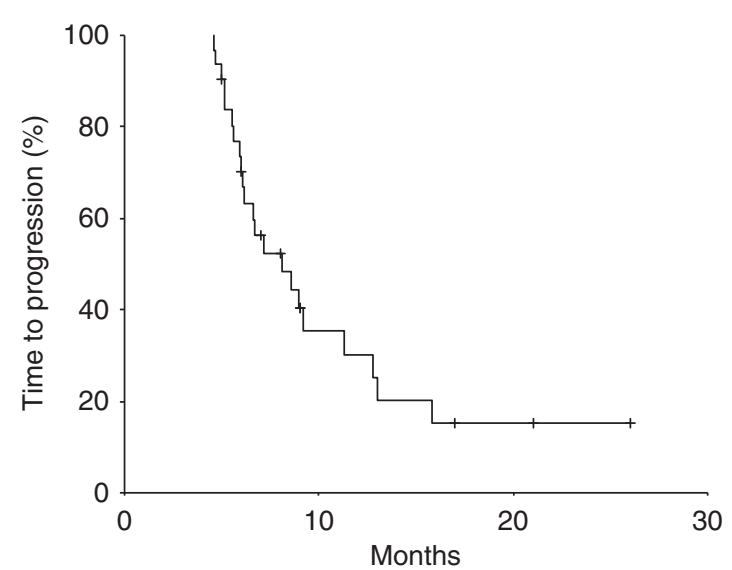

Figure I Time to progression.

Table 4 Response rate according to histotype and skin rash

\begin{tabular}{|c|c|c|c|c|c|c|c|c|c|c|}
\hline Response & \multicolumn{2}{|c|}{ Intestinal (no. 37) } & \multicolumn{2}{|c|}{ Non-intestinal (no. 3I) } & & \multicolumn{2}{|c|}{ Skin rash $<2$ (no. 36) } & \multicolumn{2}{|c|}{ Skin rash $\geqslant 2($ no. 32$)$} & \\
\hline$P R$ & 16 & 43.2 & 11 & 35.5 & & 11 & 30.6 & 16 & 50 & \\
\hline ORR (95\% Cl) & 17 & $45.9(33.1-58.7)$ & 11 & $35.5(13.6-35.7)$ & $P=0.27$ & 11 & $30.6(\mid 0.7-31.8)$ & 17 & $53.1(24.5-49.3)$ & $P=0.05$ \\
\hline SD & 14 & 37.8 & 10 & 32.3 & & 11 & 30.6 & 13 & 20.3 & \\
\hline PD & 6 & 16.2 & 10 & 32.3 & & 14 & 38.9 & 2 & 6.2 & \\
\hline
\end{tabular}




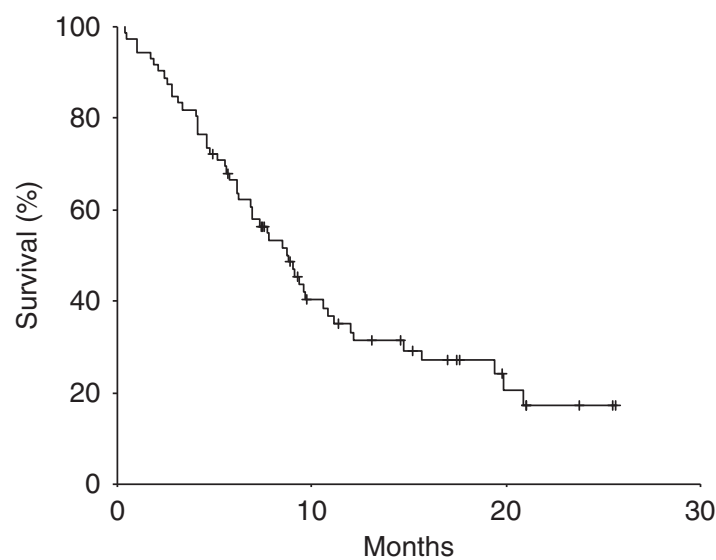

Figure 2 Overall survival.

Table 5 Toxicity

\begin{tabular}{|c|c|c|c|c|}
\hline \multirow[b]{3}{*}{ Toxicity } & \multicolumn{4}{|c|}{ No. 72} \\
\hline & \multicolumn{2}{|c|}{ All grades } & \multicolumn{2}{|c|}{ Grades 3-4 } \\
\hline & No. & $\%$ & No. & $\%$ \\
\hline \multicolumn{5}{|l|}{ Haematological toxicity } \\
\hline Neutropenia & 41 & 56.9 & 32 & 44.4 \\
\hline Febrile neutropenia & NA & - & 14 & 19.4 \\
\hline Anemia & 29 & 40.3 & 4 & 5.6 \\
\hline Thrombocytopenia & 13 & 18.1 & 2 & 2.8 \\
\hline \multicolumn{5}{|l|}{ Non-haematological toxicity } \\
\hline Acne-like rash & 51 & 70.8 & 12 & 16.7 \\
\hline Diarrhea & 23 & 31.9 & 3 & 4.2 \\
\hline Asthenia & 45 & 62.5 & 12 & 16.7 \\
\hline Stomatitis & 26 & 36.1 & 3 & 4.2 \\
\hline Hypertransaminasemia & 11 & 15.3 & 0 & - \\
\hline Hyperbilirubinemia & 10 & 13.9 & 3 & 4.2 \\
\hline Vomiting & 22 & 30.6 & 6 & 8.3 \\
\hline Anorexia & 28 & 38.9 & 2 & 2.8 \\
\hline Nausea & 35 & 48.6 & 8 & 11.1 \\
\hline Alopecia & 33 & 45.8 & NA & - \\
\hline Hypoacusia & I & 4.2 & 0 & - \\
\hline Neurotoxicity & 4 & 5.6 & I & 1.4 \\
\hline Hypomagnesemia $^{a}$ & 20 & 62.5 & I & 3.1 \\
\hline Hyponatremia ${ }^{a}$ & 14 & 43.8 & 8 & 25 \\
\hline Hypokalemia $^{a}$ & 11 & 34.4 & 4 & 12.5 \\
\hline
\end{tabular}

$\mathrm{NA}=$ not applicable. ${ }^{\mathrm{a}}$ Data available in 32 patients.

vs $6.6(95 \% \mathrm{CI}, 5.3-6.7)(P=0.10)$, and $\mathrm{OS}$ of 19.8 months (95\% CI, 12.3-27.4) vs 7.7 (95\% CI: $5.1-10.3)(P=0.22)$.

\section{Safety}

All 72 patients were evaluated for toxicity (Table 5). The major toxicity observed was haematological. Grades 3-4 neutropenia occurred in 32 patients $(44.4 \%)$. Febrile neutropenia was recorded in $14(19.4 \%)$ patients. Overall, non-haematological toxicities were moderate, and severe episodes were rare. The most common grades 3-4 non-haematological toxicities were asthenia $(16.7 \%)$, hypokalemia $(12.5 \%)$, vomiting $(8.3 \%)$, stomatitis $(4.2 \%)$, and diarrhoea $(4.2 \%)$. Cetuximab-related hypersensivity reaction was reported in 2 patients $(2.8 \%)$. All grades of acne-like rash occurred in 51 patients $(70.8 \%)$, and grades $3-4$ was observed in $12(16.7 \%)$. Grades 1-4 of hypomagnesemia was recorded in 20 of 32 patients with available data (62.5\%), and grades $3-4$ was observed in only 1 patient $(3.1 \%)$.
Eight deaths occurred within 60 days from the start of therapy: one due to bowel occlusion, one due to bowel perforation, one due to gastric bleeding, and five due to progression of disease. No toxic death was observed.

\section{Collateral studies}

KRAS and BRAF mutational status was evaluated in 32 of 72 patients (44.4\%). KRAS mutations were detected in $3(9.4 \%)$ of the tumours analysed. Two cases displayed amino acid substitutions of codon 12 and 1 of codon 13. No BRAF mutations were found. In this patient cohort, oncogenic activation of KRAS was not significantly associated with the objective response.

The data of early 18F-FDG-PET assessment will be reported in a subsequent publication.

\section{DISCUSSION}

Unresectable advanced or metastatic gastric cancer still has a poor prognosis, with a median survival of $<12$ months. A recent metaanalysis has confirmed that 5-fluorouracil-based regimens provide superior survival in patients with advanced gastric cancer as compared with those treated with the best supportive care (HR, $0.39 ; 95 \% \mathrm{CI}, 0.28-0.52$ ). This meta-analysis found a statistically significant advantage in survival $(P=0.001)$ in favour of combination chemotherapy compared with a single agent (HR, 0.83 ; $95 \%$ CI, $0.74-0.93$ ). In addition, combination chemotherapy regimens containing 5-fluorouracil, anthracycline, and cisplatin were associated with a significant survival benefit when compared with 5-fluorouracil and anthracycline regimens without cisplatin (HR, 0.83; 95\% CI, 0.76-0.91) (Wagner et al, 2006).

Recently developed new agents, such as docetaxel, irinotecan, oxaliplatin, capecitabine, and S-1, have been investigated in phase III clinical trials (Van Cutsem et al, 2006; Cunningham et al, 2008; Dank et al, 2008; Koizumi et al, 2008; Ajani et al, 2009; Kang et al, 2009). Although some combinations, such as epirubicin, oxaliplatin, and capecitabine (EOX) in a REAL 2 study, have been shown to be an interesting as well as effective regimen (overall survival 11.2 months; HR, 0.80; 95\% CI, 0.66-0.97; $P=0.02$, compared con ECF) (Cunningham et al, 2008), no worldwide standard regimens have been established.

In the three-arm SAKK42/99 phase II study, the patients as firstline treatment of advanced gastric cancer were randomised to receive the DC regimen (docetaxel at a dose of $85 \mathrm{mg} \mathrm{m}^{-2}$ on day 1 and cisplatin at a dose of $75 \mathrm{mg} \mathrm{m}^{-2}$ on day 1), or the DCF regimen (docetaxel at a dose of $75 \mathrm{mg} \mathrm{m}^{-2}$, cisplatin at a dose of $75 \mathrm{mg} \mathrm{m}^{-2}$ on day 1 , and 5-fluorouracil at a dose of $300 \mathrm{mg} \mathrm{m}^{-2}$ per day as a continuous infusion on days 1-14), or the ECF regimen (epirubicin at a dose of $50 \mathrm{mg} \mathrm{m}^{-2}$, cisplatin at a dose of $60 \mathrm{mg} \mathrm{m}^{-2}$ on day 1 , and 5 -fluorouracil at a dose of $200 \mathrm{mg} \mathrm{m}^{-2}$ per day as a continuous infusion on days 1-21) every 3 weeks. In the preliminary results on 119 patients, the ORR, TTP, and OS of DC vs DCF vs ECF were 18.5 vs 36.6 vs $25 \%, 4.4$ vs 7.8 vs 5.4 months, and 11 vs 10.4 vs 8.2 months, respectively. Grades 3-4 neutropenia was observed in $49 \%$ on the DC arm, $57 \%$ on the TCF arm, and $34 \%$ on the ECF arm. Gastrointestinal grades 3-4 toxicities (diarrhoea, stomatitis) were observed in $3 \%$ on the DC arm, $22 \%$ on the TCF arm, and $11 \%$ on the ECF arm (Roth et al, 2007).

In phase II of the V-325 study, first-line DC (docetaxel at a dose of $85 \mathrm{mg} \mathrm{m}^{-2}$ on day 1 and cisplatin at a dose of $75 \mathrm{mg} \mathrm{m}^{-2}$ on day 1) and DCF (docetaxel at a dose of $75 \mathrm{mg} \mathrm{m}^{-2}$, cisplatin at a dose of $75 \mathrm{mg} \mathrm{m}^{-2}$ on day 1 , and 5-fluorouracil at a dose of $750 \mathrm{mg} \mathrm{m}^{-2}$ per day as a continuous infusion on days $1-5$ ), both administered every 3 weeks, were compared in 158 patients with advanced gastric or GEJ adenocarcinoma. Both regimens were active. ORR, TTP, and OS of DC vs DCF were 26 vs 43\%, 5.0 vs 
5.9 months, and 10.5 vs 9.6 months, respectively. The most frequent grades 3-4 adverse events were neutropenia (87\% in the DC group vs $86 \%$ in the DCF group) and gastrointestinal toxicities (30\% in the DC group vs $56 \%$ in the DCF group) (Ajani et al, 2005). In phase III of the V-325 trial, a total of 445 patients were randomised and treated with DCF every 3 weeks or with CF (cisplatin at a dose of $100 \mathrm{mg} \mathrm{m}^{-2}$ on day 1 , and 5-fluorouracil at a dose of $1000 \mathrm{mg} \mathrm{m}^{-2}$ per day as a continuous infusion on days $1-5$ ), every 4 weeks. All efficacy end points, TTP (primary end point), OS, and ORR, were found to be significantly improved in the DCF arm vs the CF arm 5.6 vs 3.7 months, (HR, 1.47; 95\% CI, $1.19-1.82 ; P<0.001$ ), 9.2 vs 8.6 months (HR, 1.29; 95\% CI, $1.0-1.6$; $P=0.02)$, and 37 vs $25 \%(P=0.01)$, respectively. DCF was associated with increased toxicity, compared with $\mathrm{CF}$, especially grades 3-4 neutropenia (82.3 vs $56.8 \%$ ), and febrile neutropenia (30 vs $13.5 \%)$ (Van Cutsem et al, 2006). Following the results of V-325, several variations of DCF have been reported with different administration schedules, alternative platinum and fluoropyrimidine components to try to optimise both efficacy and safety (Park et al, 2005; Orditura et al, 2006; Lorenzen et al, 2007; Tebbutt et al, 2007).

Molecular targeting agents are another new topic in the field of cancer therapy, and may provide a significant impact also in gastric cancer treatment, as successful results have been observed in colorectal cancer. An increase of EGFR protein expression in gastric cancer appears to be related to biological aggressiveness, although gene amplification has occurred only to a small extent (Tokunaga et al, 1995; Albanell et al, 2001; Mendelsohn, 2002; Takehana et al, 2003). Numerous studies have established that gastric cancer has overexpressed many growth factors and their receptors, including the EGF family, and numerous cytokines, such as transforming growth factor (Zheng et al, 2004). The presence of EGF in gastric cancer is correlated with the degree of gastric wall invasion and lymph node metastasis. The 5-year survival of patients with EGF-positive tumours is worse than that of patients with EGF-negative tumours (Albanell et al, 2001; Mendelsohn, 2002; Takehana et al, 2003). A recent study has shown that hereditary diffuse gastric cancer-associated E-cadherin germline missense mutations lead to increased EGFR activity (Moutinho et al, 2008). Several phase II trials have reported on the promising clinical activity of cetuximab in combination with chemotherapy. The chemotherapy regimens included irinotecan (FOLFIRI, FUFIRI), oxaliplatin (FUFOX, FOLFOX, XELOX), and cisplatin (capecitabine/cisplatin). All chemotherapy regimens contained a fluoropyrimidine. The ORR varied from 40 to $67 \%$ in these phase II studies (Pinto et al, 2007; Lordick et al, 2007; Han et al, 2008; Zhang et al, 2008; Han et al, 2009; Yeh et al, 2009; Kanzler et al, 2009).

In the DOCETUX study, the addition of cetuximab to the DC regimen (cisplatin and docetaxel at a dose of $75 \mathrm{mg} \mathrm{m}^{-2}$ for both drugs) was associated with an improvement in the ORR compared with the results obtained by the regimen DC alone in randomised phase II studies. The ORR was $41.2 \%$ of DC plus cetuximab in the DOCETUX study, and 18.5 and $26 \%$, respectively, of DC alone in the SAKK42/99 and V-325 studies. The DC plus cetuximab treatment achieved the same ORR in both different histotypes, intestinal and non-intestinal adenocarcinoma. We observed a trend (not statistically significant) between treatment activity and the severity of cetuximab-induced skin reactions, as reported in the other study with cetuximab-based therapy (Cunningham et al,
2004; Jonker et al, 2007; Pinto et al, 2007; Bokemeyer et al, 2009). An additional finding was that the DC plus cetuximab regimen resulted in a short time to response (median 6 weeks). This suggests that this combination may also be a potentially effective treatment in a neoadjuvant setting, where a rapid tumour reduction before curative surgery is important. Three patients in the DOCETUX trial (two with locally advanced disease and 1 with peritoneal metastases) have obtained remission after treatment that has permitted radical surgery.

In this study, we have a marginal increase in TTP (5 months) and lack of improvement in OS (9 months). These OS data may be the result of the unfavourable characteristics of the patients: $43.1 \%$ with non-intestinal histotype (77.4\% with signet ring cells), $95.8 \%$ with metastatic disease, and $76.4 \%$ with $\geqslant 2$ organs involved. Furthermore, the median age of the patients was 63 years and $39 \%$ of the patients were $\geqslant 65$ years old (higher than the V-325 study with a median age of 55 years and $24 \%$ of patients $\geqslant 65$ years old (Van Cutsem et al, 2006). Although the analysis was not planned, this study suggests a non-statistically significantly favourable disease control trend in patients treated with cetuximab maintenance compared with patients without maintenance treatment (TTP 9.2 vs 6.6 months; OS 19.8 vs 7.7 months). The possibly favourable impact on TTP and OS of cetuximab maintenance treatment in patients who had at least stable disease after chemotherapy plus cetuximab therapy was also suggested by the results of our earlier phase II study in advanced gastric cancer patients treated with FOLFIRI plus cetuximab (FOLCETUX Study) (Pinto et al, 2007) and phase III study in recurrent or metastatic head and neck cancer patients treated with platinum-based chemotherapy plus cetuximab (EXSTREME Study) (Vermorken et al, 2008).

The major toxicity of the DOCETUX treatment appears to be limited to neutropenia ( $44.4 \%$ of grades $3-4$, with $19.4 \%$ of febrile neutropenia). Gastrointestinal toxicities (stomatitis, diarrhoea) were modest $(8.4 \%)$. Overall, the side effects were moderate. The toxicity of DC chemotherapy was unaffected by the addition of cetuximab. The percentage of grades 3-4 neutropenia in the DOCETUX regimen was lower that in the DC regimen of the SAKK $42 / 99$ study $(76 \%$ of grades $3-4$, with $21 \%$ of febrile neutropenia) and V-325 study (87\% grades $3-4$, with $27 \%$ of febrile neutropenia). These data could be related to a lower dose of cisplatin $\left(75 \mathrm{mg} \mathrm{m}^{-2}\right)$ in the DOCETUX study. The specific side effects associated with cetuximab were skin reactions $(70.8 \%$ all grades, and $16.7 \%$ of grades $3-4)$, infusion-related reactions $(2.8 \%$ of grade 3$)$, and hypomagnesemia (62.5\% all grades, and $1.4 \%$ of grades $3-4)$. Compliance with cetuximab was good, with only two patients $(2.8 \%)$ discontinuing the treatment for grade 3 infusionrelated reactions. There were no treatment-related deaths.

In the DOCETUX phase II study, cetuximab in combination with the cisplatin/docetaxel regimen increases the ORR of the cisplatin/ docetaxel doublet and allows for a well-tolerated dose of both drugs. The lack of improvement in OS could be correlated to the unfavourable characteristics of the patients, such as the absence of a fluopyrimidine in the chemotherapy regimen. These results support new trials in the first-line regimen of advanced gastric or GEJ adenocarcinoma. Future studies should investigate the major active chemotherapy triplet with schedules of 5-fluorouracil (or oral fluopyrimidines) plus cisplatin and docetaxel in combination with cetuximab under different settings.

\section{REFERENCES}

Ajani JA, Fodor MB, Tjulandin SA, Moiseyenko VM, Chao Y, Cabral Filho S, Majlis A, Assadourian S, Van Cutsem E (2005) Phase II multiinstitutional randomized trial of docetaxel plus cisplatin with or without fluorouracil in patients with untreated, advanced gastric, or gastroesophageal adenocarcinoma. J Clin Oncol 23: 5660-5667
Ajani JA, Rodriguez W, Bodoky G, Moiseyenko V, Lichinitser M, Gorbunova V, Vynnychenko I, Garin A, Lang I, Falcon S (2009) Multicenter phase III comparison of cisplatin/S-1 (CS) with cisplatin/5FU (CF) as first-line therapy in patients with advanced gastric cancer (FLAGS). Proc ASCO GI, Abstract 8 
Albanell J, Rojo F, Baselga J (2001) Pharmacodynamic studies with the epidermal growth factor receptor tyrosine kinase inhibitor ZD 1839. Semin Oncol 28(Suppl 16): 56-66

Bokemeyer C, Bondarenko I, Makhson A, Hartmann JT, Aparicio J, de Braud F, Donea S, Ludwig H, Schuch G, Stroh C, Loos AH, Zubel A, Koralewski P (2009) Fluorouracil, leucovorin, and oxaliplatin with and without cetuximab in the first-line treatment of metastatic colorectal cancer. J Clin Oncol 10: 663-671

Bosetti C, Bertuccio P, Levi F, Lucchini F, Negri E, La Vecchia C (2008) Cancer mortality in the European Union, 1970-2003, with a joinpoint analysis. Ann Oncol 19: 631-640

Ciardiello F, Tortora G (2001) A novel approach in the treatment of cancer: targeting the epidermal growth factor receptor. Clin Cancer Res 7: $2958-2970$

Cunningham D, Humblet Y, Siena S, Khayat D, Bleiberg H, Santoro A, Bets D, Mueser M, Harstrick A, Verslype C, Chau I, Van Cutsem E (2004) Cetuximab monotherapy and cetuximab plus irinotecan in irinotecan-refractory metastatic colorectal cancer. $N$ Engl J Med 351: $337-345$

Cunningham D, Starling N, Rao S, Iveson T, Nicolson M, coxon F, Middleton G, Daniel F, Oates J, Norman AR, Upper Gastrointestinal Clinical Studies Group of the National Cancer Research Institute of the United Kingdom (2008) Capecitabine and oxaliplatin for advanced esophagogastric cancer. $N$ Engl J Med 358: 36-46

Dank M, Zaluski J, Barone C, Valvere V, Yalcin S, Peschel C, Wenczl M, Goker E, Cisar L, Wang K, Bugat R (2008) Randomized phase III study comparing irinotecan combined with 5-fluorouracil and folinic acid to cisplatin combined with 5-fluorouracil in chemotherapy naive patients with advanced adenocarcinoma of the stomach or esophagogastric junction. Ann Oncol 19(8): 1450-1457

Garcia M, Ward EM, Center MM (2007) Global Cancer Facts and Figures 2007 [online]. Accessed August 20, 2008. URL: www.cancer.gov

Han S, Park R, Lee K, Song H, Kim MA, Oh D, Im S, Kim W, Bang Y, Kim T (2008) Phase II study and biomarker analysis of cetuximab in combination with oxaliplatin, 5-fluorouracil, leucovorin as first-line treatment in patients with recurrent or metastatic gastric cancer. J Clin Oncol 26: 15S, Proc ASCO, Abstract 4549

Han SW, Oh DY, Im SA, Park SR, Lee KW, Song HS, Lee NS, Lee KH, Choi IS, Lee MH, Kim MA, Kim WH, Bang YJ, Kim TY (2009) Phase II study and biomarker analysis of cetuximab combined with modified FOLFOX6 in advanced gastric cancer. Br J Cancer 100: $298-304$

Jonker DJ, O'Callaghan CJ, Karapetis CS, Zalcberg JR, Tu D, Au HJ, Berry SR, Krahn M, Price T, Simes RJ, Tebbutt NC, van Hazel G, Wierzbicki R, Langer C, Moore MJ (2007) Cetuximab for the treatment of colorectal cancer. N Engl J Med 357: 2040-2048

Kang YK, Kang WK, Shin DB, Chen J, Xiong J, Wang J, Lichinitser M, Guan Z, Khasanov R, Zheng L, Philco-Salas M, Suarez T, Santamaria J, Forster G, McCloud PI (2009) Capecitabine/cisplatin vs 5-fluorouracil/ cisplatin as first-line therapy in patients with advanced gastric cancer: a randomised phase III noninferiority trial. Ann Oncol 20: 666-673

kanzler S, Trarbach T, Seufferlein T, Kubicka S, Lordick F, Geissler M, Daum S, Galle P, Moehler MH, AIO Gastric group, Germany (2009) Cetuximab with irinotecan/folinic acid/5-FU as first-line treatment in advanced gastric cancer: A nonrandomized multicenter AIO phase II study. Preliminary results of a nonrandomised multi-centre AIO phase II study. J Clin Oncol 27: 15s, Proc ASCO, Abstract 4534

Kaplan EL, Meier P (1958) Non-parametric estimation from incomplete observation. J Am Stat Assoc 53: 457-481

Kelley JR, Duggan JM (2003) Gastric cancer epidemiology and risk factors. J Clin Epidemiol 56: 1-9

Koizumi W, Narahara H, Hara T, Takagane A, Akiya T, Takagi M, Miyashita K, Nishizaki T, Kobayashi O, Takiyama W, Toh Y, Nagaie T, Takagi S, Yamamura Y, Yanaoka K, Orita H, Takeuchi M (2008) S-1 plus cisplatin versus S-1 alone for first-line treatment of advanced gastric cancer (SPIRITS trial): a phase III trial. Lancet Oncol 9: 215-221

Lordick F, Lorenzen S, Hegewisch-Becker S, Folprecht G, Wöll E, Decker T, Endlicher E, Röthling N, Fend F, Peschel C (2007) Cetuximab plus weekly oxaliplatin/5FU/FA (FUFOX) in 1st line metastatic gastric cancer. Final results from a multicenter phase II study of the AIO upper GI study group. J Clin Oncol 25: 18S, Proc ASCO, Abstract 4526

Lorenzen S, Hentrich M, Haberl C, Heinemann V, Schuster T, Seroneit T, Roethling N, Peschel C, Lordick F (2007) Split-dose docetaxel, cisplatin and leucovorin/fluorouracil as first-line therapy in advanced gastric cancer and adenocarcinoma of the gastroesophageal junction: results of a phase II trial. Ann Oncol 18: 1673-1679
Malvezzi M, Bosetti C, Negri E, La Vecchia C, Decarli A (2008) Cancer Mortality in Italy, 1970-2002. Tumori 94: 640-657

Mendelsohn J (2002) Targeting the epidermal growth factor receptor for cancer therapy. J Clin Oncol 20: 1-13

Moutinho C, Mateus AR, Milanezi F, Carneiro F, Seruca R, Suriano G (2008) Epidermal growth factor receptor structural alterations in gastric cancer. BMC Cancer 8: 10

Nakata E, Hunter N, Mason K, Fan Z, Ang KK, Milas L (2004) C225 antiepidermal growth factor receptor antibody enhances the efficacy of docetaxel chemoradiotherapy. Int J Radiat Oncol Biol Phys 59: $1163-1173$

National Cancer Institute (NCI) (2006) Common Terminology Criteria for Adverse Events (CTCAE) version 3.0, 9 August

Orditura M, Martinelli E, Galizia G, Carlomagno C, Aurilio G, Vecchione L, Lieto E, De Placido S, Catalano G, Ciardiello F, De Vita F (2006) Weekly docetaxel and capecitabine is not effective in the treatment of advanced gastric cancer: a phase II study. Ann Oncol 17: 1529-1532

Park SR, Chun JH, Kim YW, Lee JH, Choi IJ, Kim CG, Lee JS, Bae JM, Kim HK (2005) Phase II study of lowdose docetaxel/fluorouracil/cisplatin in metastatic gastric carcinoma. Am J Clin Oncol 28: 433-438

Parkin DM, Bray F, Ferlay J, Pisani P (2005) Global cancer statistics, 2002. CA Cancer J Clin 55: 74-108

Pinto C, Di Fabio F, Siena S, Cascinu S, Rojas Llimpe FL, Ceccarelli C, Mutri V, Giannetta L, Giaquinta S, Funaioli C, Berardi R, Longobardi C, Piana E, Martoni AA (2007) Phase II study of cetuximab in combination with FOLFIRI in patients with untreated advanced gastric or gastroesophageal junction adenocarcinoma (FOLCETUX study). Ann Oncol 18: $510-517$

Roth AD, Fazio N, Stupp R, Falk S, Bernhard J, Saletti P, Köberle D, Borner MM, Rufibach K, Maibach R, Wernli M, Leslie M, Glynne-Jones R, Widmer L, Seymour M, de Braud F, Swiss Group for Clinical Cancer Research (2007) Docetaxel-cisplatin-5FU (TCF) versus docetaxel-cisplatin (TC) versus epirubicin-cisplatin-5FU (ECF) as systemic treatment for advanced gastric carcinoma (AGC): a randomized Phase II trial of the Swiss Group for Clinical Cancer Research (SAKK). J Clin Oncol 25: $3217-3223$

Simon R (1989) Optimal two-stages designs for phase II clinical trials. Control Clin Trials 10: $1-10$

Sobrero AF, Maurel J, Fehrenbacher L, Scheithauer W, Abubakr YA, Lutz MP, Vega-Villegas ME, Eng C, Steinhauer EU, Prausova J, Lenz HJ, Borg C, Middleton G, Kröning H, Luppi G, Kisker O, Zubel A, Langer C, Kopit J, Burris III HA (2008) EPIC: phase III trial of cetuximab plus irinotecan after fluoropyrimidine and oxaliplatin failure in patients with metastatic colorectal cancer. J Clin Oncol 26: $2311-2319$

Steiner P, Joynes C, Bassi R, Wang S, Tonra JR, Hadari YR, Hicklin DJ (2007) Tumor growth inhibition with cetuximab and chemotherapy in non-small cell lung cancer xenografts expressing wild-type and mutated epidermal growth factor receptor. Clin Cancer Res 13: 1540-1551

Takehana T, Kunitomo K, Suzuki S, Kono K, Fujii H, Matsumoto Y, Ooi A (2003) Expression of epidermal growth factor receptor in gastric carcinomas. Clin Gastroenterol Hepatol 1: 438-445

Tebbutt N, Sourjina T, Strickland A, Van Hazel G, Ganju V, Gibbs D, Gebski V, Munro S, Cummins M (2007) ATTAX: randomized multicenter phase III study evaluating weekly docetaxel based chemotherapy combinations in advanced esophago-gastric cancer, final results of an AGITG trial. J Clin Oncol 23: 16S, Proc ASCO, Abstract 4528

Therasse P, Arbuck SG, Eisenhauer EA, Wanders J, Kaplan RS, Rubinstein L, Verweij J, Van Glabbeke M, van Oosterom AT, Christian MC, Gwyther SG (2000) New guidelines to evaluate the response to treatment in solid tumors: European Organization for Research and Treatment of Cancer, National Cancer Institute of the United States, National Cancer Institute of Canada. J Natl Cancer Inst 92: 205-216

Tokunaga A, Onda M, Okuda T, Teramoto T, Fujita I, Mizutani T, Kiyama T, Yoshiyuki T, Nishi K, Matsukura N (1995) Clinical significance of epidermal growth factor (EGF), EGF receptor, and c-erbB-2 in human gastric cancer. Cancer 75: 1418-1425

Van Cutsem E, Köhne CH, Hitre E, Zaluski J, Chang Chien CR, Makhson A, D’Haens G, Pintér T, Lim R, Bodoky G, Roh JK, Folprecht G, Ruff P, Stroh C, Tejpar S, Schlichting M, Nippgen J, Rougier P (2009) Cetuximab and chemotherapy as initial treatment for metastatic colorectal cancer. N Engl J Med 360: 1408-1417

Van Cutsem E, Moiseyenko VM, Tjulandin S, Majlis A, Constenla M, Boni C, Rodrigues A, Fodor M, Chao Y, Voznyi E, Rise ML, Ajani JA, V325 Study Group (2006) Phase III study of docetaxel and cisplatin plus 
fluorouracil compared with cisplatin and fluorouracil as first-line therapy for advanced gastric cancer: a report of the V325 Study Group. J Clin Oncol 24: 4991 - 4997

Vermorken JB, Mesia R, Rivera F, Remenar E, Kawecki A, Rottey S, Erfan J, Zabolotnyy D, Kienzer HR, Cupissol D, Peyrade F, Benasso M, Vynnychenko I, De Raucourt D, Bokemeyer C, Schueler A, Amellal N, Hitt R (2008) Platinum-based chemotherapy plus cetuximab in head and neck cancer. $N$ Engl J Med 359: 1116-1127

Wagner AD, Grothe W, Haerting J, Kleber G, Grothey A, Fleig WE (2006) Chemotherapy in advanced gastric cancer: a systematic review and metaanalysis based on aggregate data. J Clin Oncol 24: 2903-2909
Yeh K, Hsu C, Hsu C, Lin C, Shen Y, Wu S, Chiou T, Chao Y, Cheng A (2009) Phase II study of cetuximab plus weekly cisplatin and 24-hour infusion of high-dose 5-fluorouracil and leucovorin for the first-line treatment of advanced gastric cancer. J Clin Oncol 27: Proc ASCO, Abstract 4567

Zhang X, Xu J, Shen L, Wang J, Liang J, Xu N, Bai Y, Wang J (2008) A phase II study of cetuximab (Cetuximab) with cisplatin and capecitabine (Xeloda) as 1st line treatment in advanced gastric cancer. J Clin Oncol 26: 15S, Proc ASCO, Abstract 15663

Zheng L, Wang L, Ajani J, Xie K (2004) Molecular basis of gastric cancer development and progression. Gastric Cancer 7: 61-77 